\title{
The Teaching Reform of Course Practice of "Enterprise Image" Based on New Media Application
}

\author{
Chunyue Zhao \\ Zhuhai College of Jilin University, China.
}

Keywords: New media, enterprise image, teaching reform.

\begin{abstract}
This paper is oriented by advertising design characteristics under new media application, and focuses on students' training of innovative ability and practice ability, studies how to make the " Enterprise Image " course meet the new requirements of the television, mobile phone and other emerging media on design idea, expression forms, media, and objects, and brings new media communications and applications into teaching, explores how to make full use of design laboratory resources and out-of-school practice base resources, builds course system and teaching system which are centered on the new media application.
\end{abstract}

\section{Introduction}

The continuous development of the Internet has replaced traditional media, changed the transmission mode of information, and promoted the emergence and development of digital television and mobile phones and other new media. The emergence of new media has greatly enriched the expression forms and transmission modes of advertising design, showed a diversified development trend, and its transmission effect is more influential. The teaching of advertising design is in the form of printing and communication and so on, which has been unable to adapt to the needs of advertising design in the new media era. The era of rapid development of new media has brought unprecedented opportunities and challenges to advertising design. Colleges and universities have realized the relevant problems in the course teaching of "Enterprise Image", actively sought new ideas and new methods for course teaching, reformed the course of "Enterprise Image ", developed in a coordinated way and cultivated practical talents, and it has become problems that must be considered in the course teaching of advertising design.

\section{Characteristics of Advertising Design under New Media Applications}

The new media is to take digitization, information replace radio and newspapers and so on, which has become one of the most important forms of mass media. With the continuous expansion of transmission subject of the new media, the transmission speed of advertising is efficient and convenient, and the information transmission is more extensive, and can enable the audience to acquire a large amount of high-quality, high-efficiency information in a more proactive manner. At the same time, the market which adapts to the development of new media has increased the demand for advertising talents, which puts forward new requirements for the course teaching and personnel training of the "Enterprise Image" to some extent. The course reform of "Enterprise Image" should start from the characteristics of advertising under new media applications:

\subsection{Advertising under New Media Applications Is A High-Quality, High-Efficiency Information Complex.}

The emergence of online media has accelerated the release and acquisition time for advertising information, and has a faster information transmission and update speed. Advertising as an important part of enterprise image shaping can enhance the company's publicity and business efficiency of product.

\subsection{Advertising under New Media Applications Is Interactive.}

In essence, the realization of the enterprise image requires a good interaction between the enterprises and the users. Enterprises can issue advertising information through the Internet, users can 
actively acquire enterprise image through mobile phones, tablet computers and other terminal devices, the development of the media makes the reception of advertising information from passive to active, and can aim to integrate a large amount of information timely, objective and conscious information retrieval of target users can enable enterprises and products to interact well with users.

\subsection{Advertising under the New Media Application Have the Function of Connecting Information, Which Is Conducive to the Integration of Enterprise Image.}

For example, flat graphics applications, multi-format image conversion make advertising design more adaptable. The issue of advertising information can integrate information of multiple sources, bring new media transmission forms and application features into teaching, and meet the needs of different media and platforms in order to meet the shaping of enterprise image. In the era of new media, works produced in advertising design courses have a certain degree of social recognition, and only in this way can have a higher marketing value [1].

\section{Problems in the Course Teaching of "Enterprise Image"}

At present, the course teaching of "enterprise image" in foreign universities is mainly based on the transmission and application of new media, the course system is relatively perfect, and the teaching is practical. At home, the "Enterprise Image" course in Chinese universities still leans towards the application teaching of traditional print media, only new media majors in few colleges and universities are involved in teaching new media applications, and the course teaching has the following problems:

\subsection{The Course Structure of "Enterprise Image" Is Unreasonable and the Teaching Objectives} Are Not Clear.

The advertising design discipline has a strong practicality, the school places too much emphasis on details, the training objectives are not clear in the teaching process, the construction of the course knowledge system is unreasonable, and the students' knowledge is dispersed and difficult to achieve mastery through a comprehensive study of the subject. At this stage advertising design course teaching, some are mainly manifested in complex contents, and the decomposition of advertising design is also relatively more, and there are overlapping phenomena between them [2]. At present, "Enterprise Image" course teaching often emphasizes theory and ignores practice; course teaching does not integrate well with design practice, it ignores the development characteristics of new media and makes "Enterprise Image" course difficult to connect with society.

\subsection{The Teaching Content of The "Enterprise Image" Course Is Updated Quickly and Is Difficult to Learn.}

At present, the teaching content of the "Enterprise Image" course seldom involves "Marketing Plan" and "Marketing Management", most of them is based on VI design, it is difficult for students to grasp the relationship among CI, BI, and MI, it is difficult to perfect connect technology, process, idea and form in the process of shaping enterprise image. Students cannot grasp the relevant knowledge of the "Enterprise Image" in a timely and comprehensive manner, cannot cope with unexpected situations in advertising design, and it is difficult to mobilize the students' learning enthusiasm. The plate design of the classroom teaching is unreasonable, the student's design work cannot be combined with the market, and cannot systematically integrate and design enterprise image.

\subsection{The Course Teaching and Practice of Enterprise Image Derail.}

The development of network technology and mobile network terminals has reshaped the new pattern of media applications, changed the aesthetic orientation and behavior habits of the general public, weakened the transmission modes and audience attention of traditional advertising design, and had a profound impact on the reorganization of social relationships. New media has the characteristics of massiveness and sharing, and traditional print media cannot compete with its transmission mode of hypertext. At present, the teaching content of the "Enterprise Image" course is out of touch with the development of society, the knowledge structure of the teaching content and teaching model is aging, the key point of teaching is shifted, neglect the ability to train students' 
practical skills to the new media. The design is weak in practicality, the attention to hot issues is not high, employment is irrelevant to majors, talents are poor in practice, and talent training cannot meet the development needs of the advertising industry. In the "Enterprise Image" teaching link, emphasize visual aesthetics, ignore technical performance, cause teaching content to be relatively old, cannot keep up with the times, these restrict the reform and innovation of advertising design teaching.

\section{Practice Teaching Reform of "Enterprise Image" Course Based on the New Media Application}

Under the promotion of new media, research is conducted for the transmission forms and application characteristics of new media, understand the teaching purposes, teaching modes, and teaching content of the "Enterprise Image" course, and analyze the problems existing in the course teaching of Enterprise Image at the current stage, explore the new advertising design talents training mode adapted to new media applications, and provide some references for course teaching of advertising design. The reform of practice teaching is mainly accomplished through the following three stages:

\subsection{Set Course Teaching Goals That Are Consistent with New Media Applications.}

In order to adapt to the requirements of the new media for the training of advertising design talents, the characteristics of the new media applications must be followed in the entire process of teaching reform, formulate personnel training goals and plans with aim, improve the teaching level of teachers, and strengthen the construction of teachers and disciplines to meet the needs of society and industry development. Organize teachers to survey or study in new media companies, experience the process of design, production and marketing of new media advertising, enrich the teaching ability and practical experience of the "Enterprise Image" course, and apply the practice results continuously to the course teaching to make the reformed course more scientific, balanced, comprehensive and selective.

Through the teaching practice of "Enterprise Image" under the theory of new media applications, students' understanding of new media applications will be improved. In the teaching process of concept cognition, method experience, and ability training, the students can understand the transmission characteristics of new media such as We chat business and e-commerce, and the communication forms such as We Chat and mobile phones, master the basic characteristics and design methods of new media applications and audiences' design appeal under the background of new media, understand the learning requirements of the "Enterprise Image" course under new media applications, achieve the integration and transformation of traditional "Enterprise Image" course, improve the matching degree between the teaching content of the "Enterprise Image" course and the new media application design position.

\subsection{Optimize Teaching Process and Enrich Teaching Content.}

Follow the principle of practical applicability of advertising design, give full play to the transmission advantages of new media advertising, integrate the performance techniques and design features of new media and new technologies, systematically conduct teaching training of new media application, expand and apply the "Enterprise Image" course under the traditional media transmission theory, integrate communication, advertising, and advertising design, make course design compatible with the visual expression of new media, can also enhance students' imagination.

According to the orientation of the training of advertising design talents under the background of new media applications, colleges and universities rely on their own training advantages to establish course system adapted to the needs of new media applications, shift the focus of the course teaching of "Enterprise Image" to the application fields of new media, increase the teaching weight of new media applications, improve students' understanding of new media design forms and application characteristics, at the same time, strengthen the graphics software courses and other auxiliary teaching methods, and provide sufficient technical support for students' new media advertising design learning. For example, in graphic design, typeface design, etc. the teaching contents of new media applications are increased, do systematic research for teaching methods, teaching contents, and 
implementation strategies proposed by new media applications, and organize teaching practice. Make full use of traditional design theory and integrate flat design techniques, increase teaching content such as icons, buttons and other media elements, the layout design link is based on the combination of traditional printing materials and process teaching, increase new media content such as interface design and banner design, make full use of the $\mathrm{H} 5$ design platform to increase theoretical knowledge in the communication fields, such as We Chat business and e-commerce, and promote information exchange and resource sharing among various disciplines.

\subsection{Strengthen the Combination of Theory and Practice.}

Aim at the new media application and focus on the practicality of the course, it has largely adapted to the current employment orientation. According to the educational direction of the college and the training objectives of the major, we should train talents with multi-disciplinary comprehensive knowledge, art design skills, and master graphic design software. Make full use of school-enterprise cooperation and organized competition, shorten the gap between theory and practice, build a project-based teaching platform of course, through the project analysis, pre-investigation, form the actual task, so as to enter the teaching design stage and teaching implementation stage, and dynamically adjust the content and structure of the course in accordance with implementation feedback.

Integrate traditional education concepts and Internet thinking, obtain integral and comprehensive discipline system; aim at employment, conduct project-based teaching, intensify the practical value of the course, train innovative awareness and practical ability of creative talents, and promote employment ability of advertising design talents; under conditions permitting, teachers organize students to visit advertising companies to learn about the industry's development frontier, combine professional knowledge and professional skills; advocate students to participate in the design of the project design, and give students appropriate thinking and guidance. At the same time, train students' ability to receive and study new things, male students learn with problems and purposes, check the blind point of knowledge in theoretical learning, learn to analyze and solve problems, so as to better mobilize students' enthusiasm for learning.

\section{Conclusion}

New media advertising is an evolving concept, the reform of the course teaching of "Enterprise Image" should be guided by new media application, and the core objective is to train students' innovative ability and practical ability. Colleges and universities need to combine advertising design theory with new media applications to carry out teaching reform research, based on the integration of traditional "Enterprise Image" course teaching experience, make full use of design laboratory resources and out-of-school practice base resources, build a course system and teaching system with new media applications as the core, promote the structural transformation of traditional media courses, increase the proportion of new media application teaching, find effective teaching methods and mode for the training of advertising design talents, expect to provide feasible experience for the reform of practice teaching of "Enterprise Image" course, and train more outstanding advertising design talents.

\section{Acknowledgements}

Fund Project: Teaching Quality Project of Zhuhai College of Jilin University (ZLGC20170736)

\section{References}

[1]. Xia Lin. Discussion on the Reform and Innovation of Advertising Design Teaching in the New Media Era [J]. Art Education Research, 2013, (23): 95-97.

[2]. Yue Xu, Liu Zhuang. Research on Reform and Innovation of Advertising Design in New Media Environment [J]. Journal of Chafing University (Natural Science Edition), 2014, (15): 137-139. 